\title{
EFEITOS DA CULTURA DA CEVADA E DE PERÍODOS DE CONTROLE SOBRE O CRESCIMENTO E PRODUÇÃO DE SEMENTES DE Raphanus sativus L. ${ }^{1}$
}

\author{
JOSÉ ROBERTO PINTO DE SOUZA2 e EDIVALDO DOMINGUES VELINI3
}

RESUMO

\begin{abstract}
Este experimento teve por objetivo avaliar os efeitos da cultura da cevada e de períodos de controle das plantas daninhas sobre o crescimento e produção de sementes de Raphanus sativus. Foram considerados dois tratamentos testemunha sem controle das plantas daninhas, com e sem a cultura. Nos oito demais tratamentos, a cultura esteve sempre presente, controlando-se as plantas daninhas até $10,20,30,40,50,60,80$ e 100 dias após a emergência da cevada. A comunidade infestante da área era composta quase exclusivamente por $R$. sativus. Avaliou-se o número de plantas, acúmulos de matéria seca, número médio de frutos e sementes de nabiça por planta e por unidade de área; foram ai nda avaliados o número médio de sementes por
\end{abstract}

fruto, peso médio de 1.000 sementes e a contribuição das sementes na composição da matéria seca total. A análise dos resultados evidenciou que a espécie Raphanus sativus apresenta elevado potencial reprodutivo, sendo possível concluir pela ineficiência de programas de controle de curta duração, em termos de red ução do banco de sementes. A pre sença da cul tura da cevada reduziu tan to o cre scimento qua nto o número de sementes produzidas pela nabiça ( $R$. sativus). Na ausência da cultura e de práticas de controle foram produzidas 5.074 sementes/m', a partir de $125 \mathrm{plantas} / \mathrm{m}^{2}$ ainda presentes na colheita da cultura.

Palavras chave: Hordeum vulgare, semente, banco de sementes.

\section{ABSTRACT \\ Effects of the culture of the Barley and of periods of control on the seed production and growth of Raphanus sativus L.}

The objective of this research was to evaluate the effects of barley and weed control periods on the seed production and growth of Raphanus sativus, the major weed in the experimental area. The experiment was carried out in Botucatu, SP, Brazil. Two checks, with and without the crop, were kept weedy from seeding to harvest. In other eight treatments the crop was kept weed free up to $10,20,30,40,50,60,80$ and 100 days after emergence. It were evaluated the number of plants, the dry matter accumulation and the number of fruits and seeds per plant and per $\mathrm{m}^{2}$, the weight of 1.000 seed $\mathrm{s}$ and the percent of the seeds in the total dry matter accumulation. Raphanus sativus showed a high reproductive potential, producing 5.074 seed s/ $\mathrm{m}^{2}$ if kept without control in the absence of the crop. Barley reduced the growth and the seed production of $R$. sativus. To reduce de seed production to values lower than the population density of the $R$. sativus in the checks, the weed should be controlled up to 30-100 days after crop emergence.

Key words: Hordeum vulgare, seed, seeds bank.

I Recebido para publicação em 18/02/97 na forma revisada em 16/10/97.

2 Professor Assistente Doutor. UEL / CCA / Agronomia. Caixa Postal 6.001, CEP 86.051-990, Londrina-PR.

3 Professor Assistente Doutor. DAMV/FCA/UNESP. Caixa Postal. 237, CEP 18.603-970, Botucatu-SP. 


\section{INTRODUÇÃO}

O tamanho e a composição botânica dos bancos de sementes no solo são extremamente variáveis em distintos habitats. Normalmente, o tamanho aumenta consideravelmente de florestas a pastagens e finalmente as áreas cultivad as anualmente (Cook, 1980). Isto deve-se à estratégia das plantas daninhas de produzir grande número de sementes por planta (Mitich, 1988, Forster, 1989, Mortimer, 1990) aliado a mecanismos de dissemi nação, longevidade e dormência (Bouwme ester \& Karssen, 1989) para sobreviver em ambientes constantemente perturbados. Os es tudos de Roberts (1981), sobre banco de sementes, mostraram a presença de 1.800 a 67.000 sementes de plantas daninhas por $\mathrm{m}^{2}$ de 0 a $15 \mathrm{~cm}$ de profundidade em áreas cultivadas com cereais. Já Schweizer \& Zimdhal (1984) encontraram 2.080 a 137.700 sementes de plantas daninhas por $\mathrm{m}^{2}$ de 0 a $25 \mathrm{~cm}$ de profundidade nas culturas de cevada, milho e beterraba.

Nos solos agrícolas, as sementes das plantas da ninh as an ua is são as principa is constituintes do banco de sementes, alcançando, normalmente, $95 \%$ do total (Roberts, 1981).

Os bancos de sementes constitue m um sério problema à atividade agrícola, na medida em que garantem infestações das plantas daninhas por longo período de tempo, mesmo quando se impede a entrada de novas sementes na área (Cavers \& Benoit, 1989). A ocorrência de um "estoque" de sementes dormentes no solo, associada à superação desta dormência em distintas épocas, torna difícil prever com precisão as taxas de germinação em um determinada área agrícola, ge rando a obrigatoriedade da adoção de práticas de controle de plantas daninhas sempre que uma cultura é introduzida no local.

As tentativas de redução dos bancos de sementes através da quebra de dormência dos propágulos já presentes no solo têm se mostrado infrutíferas. Uma alternativa viável para a redução do ba nco de sementes é a mi ni mi zação da quantidade destes propágu los produzida a cada ciclo da cultura.

Quanto aos efeitos de culturas sobre o crescimento e produção de sementes de plantas daninhas, Zuin \& Zanin (1989) verificaram re du ções no porte das plantas de Abutilon theophrasti quando desenvolvida junto à cultura do milho. Peters \& Wilson (1983) verificaram que a emergência de Avena fatua, antes da cultura do milho, produziu cinco vezes mais sementes por planta do que aquelas emergidas entre os estádios de 2 e 3 folhas da cultura. Zuin \& Zanin (1989) verificaram a produção de 5.084 sementes de Abutilon theophrasti quando desenvolvidas na presença da cultura do milho, e 11.972 sementes quando na ausência da cultura. Conforme as pe squi sas de Mohler \& Callaway (1995), a produção de sementes de Amaranthus retrolexus, Chenopodium album e Portulaca oleracea foi significativamente superior na ausência das plantas de milho.

Até o momento, têm sido considerados adequados ou satisfatórios, todos os programas de controle que permitem à cultura produzir plenamente em um determinado ano agrícola. Tal posição deve ser revista pois um programa racional de controle de plantas daninhas deve também proporcionar no mínimo a manutenção e, se possível, a redução do banco de propágulos, das principais espécies, no solo.

O objetivo do presente trabalho foi avaliar os efeitos da presença da cultura da cevada e da extensão do período inicial com controle das plantas daninhas, sobre o cresciment o e produção de sementes de Raphanus sativus L.

\section{MATERIAL E MÉTODOS}

O experimento foi instalado num solo clas sificado como Terra Roxa Estruturada distrófica, textura argilosa na Fazenda Experimental Lageado, da Faculdade de Ciências 
Ag ro nômicas (FCA), Universidade Es tadual Paulista, Botucatu, SP.

O preparo do solo constou de uma aração e du as grad ag en s, se ndo a úl ti ma rea liza da imediatamente antes da semeadura. A correção do solo, com $1.000 \mathrm{~kg} / \mathrm{ha}$ de calcário dolomítico, e a adubação, com $600 \mathrm{~kg} / \mathrm{ha}$ da fórmula 4-14-8, foram realizadas considerando-se a análise do solo e as necessidades da cultura da cevada. As operações de sulcamento, adubação e semeadura foram realizadas mecanicamente. Foi empregada a cultivar PFC 7802.

TABELA 1. Descrição dos tratamentos utilizados.
Cada parcela experimental foi constituída de 13 linhas de se meadura com 4,30 m de comprimento e espaçadas de $0,17 \mathrm{~m}$. Como área útil, considerou-se os 3,90m centrais das 11 linhas internas de cada parcela. A densidade de plantas de cevada da área experimental foi de 300 plantas por metro quadrado.

Os tratamentos utilizados são descritos na Tabela 1. Os períodos de controle referem-se à emergência da cevada. As capinas foram espaçadas de dez dias nos períodos com controle das plantas daninhas.

\begin{tabular}{|c|c|c|c|c|}
\hline \multirow[t]{2}{*}{ Tratamentos } & \multirow[t]{2}{*}{ Cultura } & \multicolumn{2}{|c|}{ Períodos } & \multirow{2}{*}{$\begin{array}{c}\text { Número de } \\
\text { capinas }\end{array}$} \\
\hline & & Com controle & Sem controle & \\
\hline 1 & Ausente & $-\cdots$ & 0 a 120 dias & 0 \\
\hline 2 & Presente & -- & 0 a 120 dias & 0 \\
\hline 3 & Presente & 0 a 10 dias & 10 a 120 dias & 1 \\
\hline 4 & Presente & 0 a 20 dias & 20 a 120 dias & 2 \\
\hline 5 & Presente & 0 a 30 dias & 30 a 120 dias & 3 \\
\hline 6 & Presente & 0 a 40 dias & 40 a 120 dias & 4 \\
\hline 7 & Presente & 0 a 50 dias & 50 a 120 dias & 5 \\
\hline 8 & Presente & 0 a 60 dias & 60 a 120 dias & 6 \\
\hline 9 & Presente & 0 a 80 dias & 80 a 120 dias & 8 \\
\hline 10 & Presente & 0 a 100 dias & 100 a 120 dias & 10 \\
\hline
\end{tabular}

A comunidade infestante da área experimental foi composta quase exclusivamente por Raphanus sativus L. O delineamento experimental foi de blocos ao acaso com cinco repetições. Os dados foram submetidos à análise de variância e a comparação entre médias foi feita pelo teste de tao nível de $10 \%$ probabilidade.

A coleta das plantas daninhas dos tratamentos foi realizado ao 120 DAE. A área amostrada para a coleta das plantas daninhas foi de $1,08 \mathrm{~m}^{2}$, correspondentes a três avaliações de $0,60 \mathrm{~m} \times 0,60 \mathrm{~m}$. Cabe salientar que na data de av al ia çã o os frut os en cont ra vam-se ai nda completamente presos às plantas, dispensando a coleta de sementes da superfície do solo.

Após a coleta, as plantas de $R$. sativus fora m en ca minhad as ao labora tó rio para a eliminação do sistema radicular, limpeza da parte aérea e contagem das síliquas e sementes. Em seguida, todo material foi seco em estufa com circulação de ar a $60^{\circ} \mathrm{C}$ até atingir peso constante. Desse modo, obtiveram-se o número de plantas, acúmulo de matéria seca por planta e por unidade de área, número de frutos por planta e sementes por fruto, peso de mil sementes, número e massa de sementes por planta e por unidade de área, 
porcentagem da matéria seca de sementes em relação à matéria seca total de $R$. sativus.

\section{RESULTADOS E DISCUSSÃO}

Nas Tabelas 2 e 3 são apresentados os resultados referentes ao número de plantas, acúmulo total de matéria, acúmulos de matéria seca de sementes, núme ros de frut os e de sementes de $R$. sativus, expressos por planta e por unidade de área. São, também, apresentados os resultados de número de sementes por vagem, peso de 1.000 sementes e porcentagem da matéria seca de sementes em relação à matéria seca total.

TABELA 2. Número de plantas, acúmulo de matéria seca por planta e por unidade de área (g), número de frutos por planta e de sementes por fruto, peso de mil sementes (g) de Raphanus sativus pres entes na área sem e com cultura de cevada, bem como com a cultura mantida por períodos crescentes de ausência de plantas daninhas. Botucatu. 1990.

\begin{tabular}{|c|c|c|c|c|c|c|}
\hline Tratamentos & Plantas $/ \mathrm{m}^{2}$ & $\begin{array}{l}\text { Acúmulo } \\
\text { planta }\end{array}$ & $\begin{array}{c}\text { Mat. Seca } \\
\mathbf{m}^{2}\end{array}$ & $\begin{array}{l}\text { No frutos/ }^{\text {planta }} \\
\text { pla }\end{array}$ & $\begin{array}{l}\text { No sementes/ } \\
\text { fruto }\end{array}$ & $\begin{array}{l}\text { Peso mil } \\
\text { sementes }\end{array}$ \\
\hline Mato & 125,32 & 1,684 & 96,54 & 40,17 & 2,144 & 14,794 \\
\hline Mato+Cultura & 103,74 & 0,642 & 54,48 & 25,10 & 2,264 & 15,836 \\
\hline 1 Capina & 19,24 & 1,610 & 30,18 & 33,15 & 2,032 & 13,426 \\
\hline 2 Capinas & 12,52 & 1,688 & 16,36 & 22,22 & 1,316 & 9,490 \\
\hline 3 Capinas & 16,66 & 0,424 & 6,62 & 3,99 & 1,180 & 6,420 \\
\hline 4 Capinas & 14,46 & 0,516 & 9,70 & 8,09 & 1,312 & 7,510 \\
\hline 5 Capinas & 21,30 & 0,316 & 3,08 & 2,22 & 1,064 & 5,312 \\
\hline 6 Capinas & 35,00 & 0,422 & 8,94 & 1,90 & 1,438 & 7,124 \\
\hline 8 Capinas & 3,52 & 0,114 & 1,06 & 0,57 & 0,436 & 2,262 \\
\hline 10 Capinas & 5,18 & 0,010 & 0,14 & 0,01 & 0,000 & 0,000 \\
\hline \multicolumn{7}{|l|}{ Valores de F } \\
\hline Tratamentos & $2,88^{*}$ & $3,72 * *$ & $11,62 * *$ & $4,04 * *$ & $4,33 * *$ & $6,81^{* *}$ \\
\hline Blocos & $2,49 \bullet$ & $0,53^{\text {n.s. }}$ & $3,80^{*}$ & $1,00^{\text {n.s. }}$ & $1,16^{\text {n.s. }}$ & $1,68^{\text {n.s. }}$ \\
\hline $\mathrm{DMS}^{-}$ & 60,12 & 0,816 & 21,57 & 17,87 & 0,828 & 4,788 \\
\hline CV $(\%)$ & 157,74 & 102,97 & 88,95 & 121,84 & 58,87 & 54,57 \\
\hline
\end{tabular}

'D.M.S. (Diferença Minima Significativa).

- : * * Significativo ao nivel de $10 \% ; 5 \%$ e $1 \%$ de probabilidade. respectivamente.

n.s. Nào significativo.

Todos os tratamentos com períodos iniciais de controle iguais ou superiores a 30 dias promoveram grandes reduções em todas as características estudadas. Exceção feita ao número de sementes por vagem e ao peso de 1.000 sementes, não foram verificadas diferenças significativas entre estes tratamentos. Para estas duas características, os tratamentos com períodos de controle de 100 e 80 dias, respectivamente, diferiram significativamente, sendo sobrelevados por alguns dos tratamentos deste grupo.

Quanto aos tratamentos sem controle das plantas daninhas (com e sem a cultura) e aqueles com controle pelos perí odos de $10 \mathrm{e}$ 20 dias, foram capazes de promover grandes alterações no crescimento e reprodução das plantas de $R$. sativus.

A análise dos dados de números de plantas Planta Daninha, v. 15, n. 2, 1997. 
e acúmulos de matéria seca (por planta e por área) evidencia que a simples presença das plantas de cevada, sem que fosse m adotad as práticas de controle, reduziu em 17,23 e 43,56\% o número de plantas e os acúmulos de matéria seca por unidade de área. A característica menos afetada pela presença da cevada foi o acúmulo de matéria seca por planta, com $6,15 \%$ de redução. Os tratamentos com capinas por 10 ou 20 di as reduziram drasticamente as den sid ades populacionais da nabiça, mas as plantas sobreviventes apresentaram maior porte, indicado pelos maiores acúmulos de matéria seca por planta. Como resultado, os acúmulos de matéria seca por unidade de área foram alterados menos intensamente por estes tratamentos do que as densidades

TABELA 3. Número e massa de sementes por planta e por unidade de área e porcentagem da matéria seca de sementes em relação à matéria seca total de Raphanus sativus presentes na área sem e com cultura de cevada, bem com a cultura mantida por períodos crescentes de ausência de plantas daninhas. Botucatu. 1990.

\begin{tabular}{|c|c|c|c|c|c|}
\hline Tratamentos & $\begin{array}{l}\text { Número } \\
\text { /planta }\end{array}$ & $\begin{array}{c}\text { de sementes } \\
/ \mathbf{m}^{2}\end{array}$ & $\begin{array}{l}\text { Peso de } \\
\text { /planta }\end{array}$ & $\begin{array}{c}\text { sementes } \\
/ \mathbf{m}^{2}\end{array}$ & $\begin{array}{l}\% \text { sementes } \\
\text { na m. s. total }\end{array}$ \\
\hline Mato & 79,79 & 5074,0 & 0,968 & 70,25 & 69,78 \\
\hline Mato+Cultura & 49,57 & 2869,8 & 0,442 & 41,51 & 75,24 \\
\hline 1 Capina & 58,35 & 1153,3 & 0,642 & 15,03 & 54,10 \\
\hline 2 Capinas & 29,70 & 330,1 & 0,278 & 3,02 & 23,52 \\
\hline 3 Capinas & 5,33 & 96,7 & 0,044 & 0,66 & 10,06 \\
\hline 4 Capinas & 14,76 & 229,8 & 0,180 & 2,66 & 29,44 \\
\hline 5 Capinas & 3,38 & 84,9 & 0,028 & 0,74 & 17,88 \\
\hline 6 Capinas & 3,41 & 67,6 & 0,042 & 0,51 & 9,02 \\
\hline 8 Capinas & 0,53 & 4,9 & 0,004 & 0,04 & 0,76 \\
\hline 10 Capinas & 0,00 & 0,0 & 0,000 & 0,00 & 0,00 \\
\hline \multicolumn{6}{|l|}{ Valores de F } \\
\hline Tratamentos & $6,55^{* *}$ & $14,41^{* *}$ & $13,53 * *$ & $10,65^{* *}$ & $13,62 * *$ \\
\hline Blocos & $0,55^{\text {n.s. }}$ & $2,28 \bullet$ & $0,76^{\text {n.s. }}$ & $2,28 \bullet$ & $0,44^{\text {n.s. }}$ \\
\hline $\mathrm{DMS}^{1}$ & 26,72 & 1062,4 & 0,213 & 17,40 & 18,01 \\
\hline CV $(\%)$ & 102,21 & 100,39 & 75,88 & 121,26 & 58,22 \\
\hline
\end{tabular}

O número de frutos por planta foi reduzido pela presença da cevada, mas foram pequenos os efeitos das capinas por 10 ou 20 dias. O número de sementes por fruto foi bastante reduzid o pelo tratame nto em que o control e de plantas daninhas foi realizado pelo período de 20 dias.
Quanto ao número de sementes por planta, de maior importância e resultante das duas características anteriores, ficou evidente que a prese nça da cevad a foi capaz de reduzi -lo em $37,87 \%$. Houve, ainda, uma elevação nos valores desta característica quan do as plantas daninhas foram capinadas pelo período de 10 dias, um 
possível reflexo do maior porte das plantas neste tratamento. A realização de capinas por 20 dias permitiu alcançar valores inferiores a 30 sementes por planta; como já foi mencionado a miminização desta característica só ocorreu para períodos de controle superiores a 30 dias.

No tratamento sem a cultura foram produzidas mais de 5.000 sementes por $\mathrm{m} 2$, indicando que em áreas de pousio o banco de sementes desta espécie poderia ser bastante aumentado em um intervalo de tempo relativamente curto (quatro meses). A simples presença da cultura reduziu em $43,44 \%$ o número de sementes produzidas por unidade de área. Acrescentando-se o controle por 10 ou 20 dias, tais reduções alcançaram 77,27 e 93,49\%, respectivamente.

Deve ser destacado que embora o potencial de produção de sementes tenha sido intensamente reduzido pelas capinas, mesmo em tratamentos com períodos inicias com controle de até 60 dias, foram produzidas sementes em números inferiores, mas próximos às densidades populacionais observadas nas parcelas sem capina. Este comportamento evidencia o grande potencial reprodutivo desta espécie, mesmo em condições desfavoráveis ao seu crescimento e desenvolvimento.

Os pesos de sementes por planta e por unidade de área apresentaram comportamentos bastante similares aos observados para o número de sementes por planta e por $\mathrm{m}^{2}$, respectivamente. A participação das sementes na composição do acúmulo total de matéria seca foi reduzida pela realização de capinas e, de modo geral, o efeito foi tão mais intenso quanto mai or a exten são do período inicial com controle das plantas daninhas.

A análise conjunta de todos os resultados e da literatura disponível evidencia que possíveis tratamentos referentes ao controle de plantas daninhas devem ser avaliados não somente quanto à produtividade da cultura, mas também quanto ao potencial reprodutivo das espécies que compõem a comunidade infestante. A espécie Raphanus sativus apresenta elevado potencial reprodutivo, sendo possível concluir pela ineficiê ncia de programas de controle de cu rta duração, em termos de redução do banco de sementes. A presença da cultura da cevada reduziu tanto o crescimento quan to o número de sementes produzidas pela nabiça ( $R$. sativus).

\section{LITERATURA CITADA}

BAKER, H. G. Some aspects of natural history of seed banks. In: LECK, M. A., PARKER, V.T. (ed.) Ecology of Soil Seed Banks. New York: Academic Presss, 1989. p.9-21.

BOUWMEESTER, H.J., KARSSEN, C.M. Environmental factors influencing the expression of dormancy patterns in weed seeds. An. Bot., v.63, p.113-120, 1989.

CAVERS, P.B., BENOIT, D.L. See d banks in arable land. In: LECK, M.A., PAR KER, V.T. (ed.) Ecology of Soil Seed Banks. New York: Academic Presss,1989. p.309328.

COOK, R. The biology of seeds in the soil. In: SOLBRIG, O.T. (ed.). Demography and Evolution in Plant Populations. Berkeley: University of California Press, 1980. p.107-129.

FORSTER, L. The biology and non - chemical control of dock species Rumex obtusifolius and R. crispus. Biol. Agric. Hortic., v.6, p.11-25, 1989.

MITICH, L. W. Intriguing world of weeds. Common Lambsquarters. Weed Technol., v.2, p.550-552, 1988.

MOHLER, C.L., CALLAWAY, M.B. Effects of

Planta Daninha, v. 15, n. 2, 1997. 
tillage and mulch on weed seed production and seed banks in sweet corn. J. Appl. Ecol., v. 32, p. 627-639, 1995.

MORTINER, A. M. The biology of weeds. In: HANCE, R.J., HOLLY, K. (ed.). Weed Control Handbook: Principles. 8 ed. Blackwell: Scientific Publications, 1990. p.142.

PETERS, N.C.B., WILSON, B.J. Some studies on the competition between Avena fatua $\mathrm{L}$. and spring barley. H. Varation of A. fatua emergence and development and its influence on crop yield. Weed Res., v.23, p.305-311, 1983.

PINTLE, C., CHIRILLA, C. Weeds in agricultural crops (XIV). Couchgrass [Agropyron repens (L.) P.B.J. Cereale Plante Tchnice Produc. Veg., v.3 7, p.41-44, 1985. In: Weed Abstr., v.37, p.455, 1988 (Abstract n. 2977).

ROBERTS, H. A. Seed banks in soils. Adv. Appl. Biol., v.6, p.1-55, 1981.

SCHWEIZER, E.E., ZIMDAHL, R.I. Weed seed decline in irrigated soil after rotation of crops and herbicides. Weed Sci., v.32, p.8489, 1984.

ZUIN, M.C., ZANIN, G. Abutilon theophrasti Medicus: growth, reproduction, phenology and possible hypothesis on its biological strate gy. Rev. Agron., v.23, p.241-248, 1989. In: Weed Abstr., v.39, p.262, 1990 (Abstract n. 2287). 